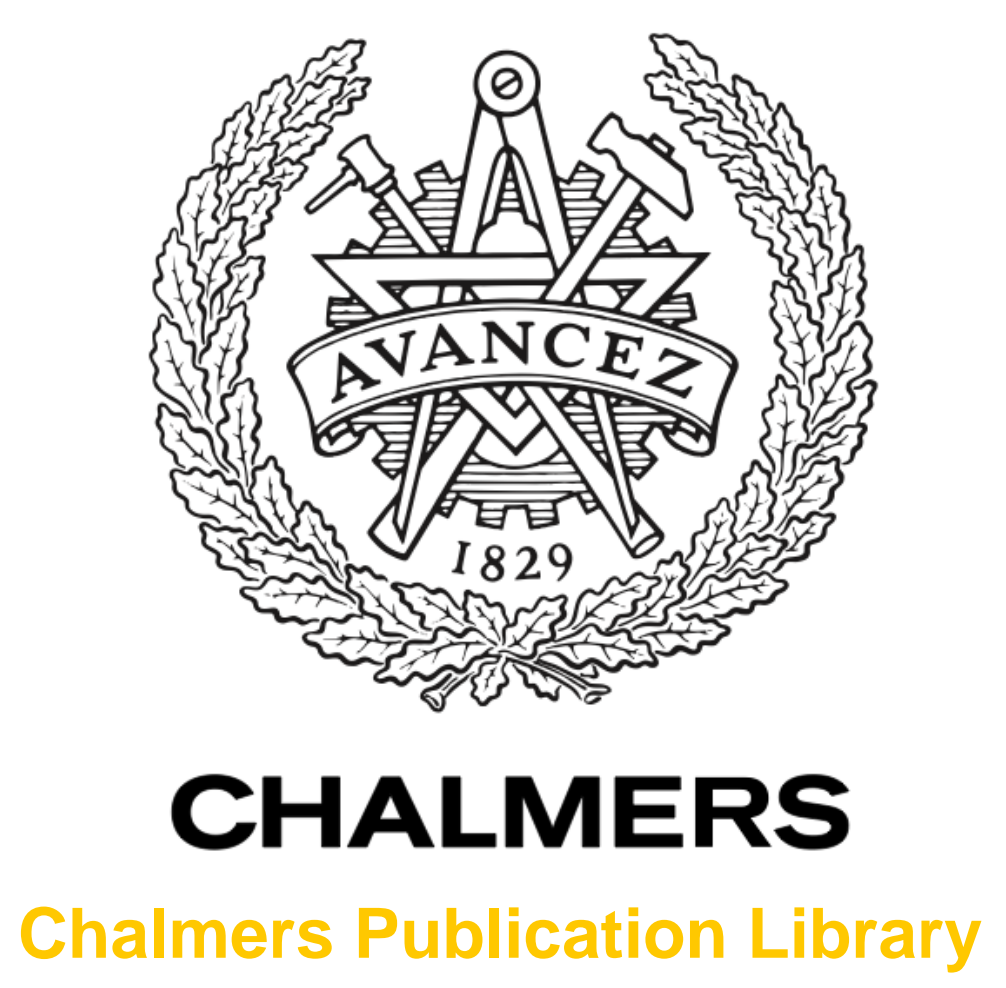

The effects of grain size and feed rate on notch wear and burr formation in wrought Alloy 718

This document has been downloaded from Chalmers Publication Library (CPL). It is the author's version of a work that was accepted for publication in:

The International Journal of Advanced Manufacturing Technology (ISSN: 0268-3768)

Citation for the published paper:

Cedergren, S. ; Nyborg, L. ; Sjöberg, G. (2012) "The effects of grain size and feed rate on notch wear and burr formation in wrought Alloy 718". The International Journal of Advanced Manufacturing Technology, vol. 67(5-8), pp. 1501-1507.

http://dx.doi.org/10.1007/s00170-012-4584-3

Downloaded from: http://publications.lib.chalmers.se/publication/170010

Notice: Changes introduced as a result of publishing processes such as copy-editing and formatting may not be reflected in this document. For a definitive version of this work, please refer to the published source. Please note that access to the published version might require a subscription.

Chalmers Publication Library (CPL) offers the possibility of retrieving research publications produced at Chalmers University of Technology. It covers all types of publications: articles, dissertations, licentiate theses, masters theses, conference papers, reports etc. Since 2006 it is the official tool for Chalmers official publication statistics. To ensure that Chalmers research results are disseminated as widely as possible, an Open Access Policy has been adopted.

The CPL service is administrated and maintained by Chalmers Library. 


\title{
The Effects of Grain Size and Feed Rate on Notch Wear and Burr Formation in Wrought Alloy 718
}

\author{
S. Cedergren ${ }^{1,2^{*}}$, S. Olovsjö ${ }^{1}$, G. Sjöberg ${ }^{1,2}$, L. Nyborg $^{1}$ \\ ${ }^{1}$ Department of Materials and Manufacturing technology, Chalmers University of \\ Technology, 41296 Göteborg, Sweden \\ ${ }^{2}$ Volvo Aero Corporation, 46130 Trollhättan, Sweden \\ *Corresponding author. Tel: +46317721244; Fax: +46317721313; E-mail: \\ stefan.cedergren@chalmers.se
}

\begin{abstract}
The effect of two different workpiece material grain sizes, $16 \mu \mathrm{m}$ and $127 \mu \mathrm{m}$, on the depth of cut notch wear, chip morphology and burr formation was studied in a turning operation. Material from the same batch of wrought superalloy Alloy 718 was heat treated to achieve the two microstructures. The machining was performed at two feed rates, 0.1 and $0.2 \mathrm{~mm} /$ revolution. Uncoated cemented carbide tools were used. Both grain size and feed rate was found to influence the chip morphology and the sideflow which were also associated both with the notch wear and the burr formation. The effect of the grain size on the notch wear was larger than that of the feed rate, with larger grains being more detrimental than smaller ones.
\end{abstract}

Keywords: Inconel 718, Metal Cutting, Superalloys, Sideflow, Chip morphology

\section{Introduction}

Superalloys are known as difficult-to-machine materials due to their high strength which is maintained at elevated temperature, low thermal conductivity, severe work hardening and high ductility [1,2]. One of the most common tool failure criteria is notch wear at the depth of cut lines and/or at the tool nose [1]. The association of the notch wear with the burr formation on the workpiece has been observed in a previous study [3]; a study which stressed the need to understand the combined effect of microstructure and cutting data. Finding the cause of burr formation, with respect to microstructure and cutting data, may allow for the elimination or minimization of burrs; desirable from an economical point of view [4].

There does not seem to be any common explanation to the notch wear at the depth of cut line. Most researchers agree that the extensive lateral material flow at the unrestricted end of the cutting zone, due to the high ductility of superalloys, is important, see e.g. $[5,6]$. The most accepted theory suggests that the notch is caused by adhesion between the tool and the chip, with subsequent pull-out of the tool material $[1,7,6,8]$. 
Lee et al. [7] suggest that it is the actual tearing at the separation of the chip from the workpiece material which allows for the formation of the ragged burr on the workpiece and the fin-shaped edge of the chip. This results in an uneven flow of material which is rubbed over the edge of the tool at high pressure and temperature which favours adhesion and with the irregular separation of work material causing pull-out of tool material. Moltrecht [6] advocates that the notch at the depth of cut line is initiated by a pull-out on the tool rake face, which spreads to the tool flank face as wear progresses. In a study by Kitagawa et al. [5] of notch wear of ceramic tools in machining of Alloy 718, they found the notch wear to be associated with the transition from a continuous type of chip to a discontinuous, segmented, one when the cutting speed was increased. The authors concluded that a large sideflow of the chip, which was also associated with burr formation on the workpiece, caused notch wear through an abrasive action as opposed to the more accepted adhesive theory. The transition from continuous chips to discontinuous ones when machining Alloy 718 has been shown by others $[9,10]$, to depend on the cutting speed as well as the feed where an increase in either or both parameters favor the discontinuous type of chips.

Literature is sparse about the influence of the microstructure of work material on tool wear and burr formation, especially in the machining of superalloys. Schirra et al. [11] investigated the influence of hardness, grain size and carbon content on the machinability of cast, cast plus hot isostatically pressed and of wrought Alloy 718. The microstructure was found to influence machinability, with large grains, high carbon content and high hardness resulting in reduced machinability with respect to tool wear. However, in this investigation, abrasive wear on tool flank was the predominant wear mechanism and no influence on notch wear was reported. The influence of grain size and hardness was specifically studied by two of the present authors [3] in a turning operation in wrought Alloy 718. The grain size was shown to impact notch wear and burr formation regardless of hardness. Small notch wear and no burr were observed when the average grain size was 16 $\mu \mathrm{m}$ (ASTM 9) while severe notch wear and large burrs were evident when the average grain size was significantly larger; $127 \mu \mathrm{m}$ (ASTM 3). A difference in chip morphology was also shown, where the small grains gave a continuous type of chip and large grains gave a more serrated type.

A conclusion that can be drawn from the literature is that the sideflow, and its shape, is important in the formation of both the notch and the burr. Another conclusion is that a transition from a continuous type of chip to a segmented one occurs when the cutting speed or feed is increased and that a similar transition from a continuous to a more unevenly deformed, i.e. a serrated one, takes place as the grain size increases. These reported observations stress the importance of both the microstructure of work material and the cutting parameters, since both affect the chip morphology and thus the characteristics of sideflow, which in turn influences both notch wear and burr formation.

The present study aims at a deeper understanding of the influence of the microstructure and especially of the grain size of the workpiece material as well as 
of the cutting parameters on the sideflow and specifically on the notch wear and the burr formation when machining Alloy 718 with cemented carbide tools.

\section{Experimental}

\section{Work material}

Alloy 718 is a nickel-iron based superalloy and is the most frequently used alloy for hot section turbine parts [2]. It is a high strength alloy capable of long service duty at a maximum temperature of $650{ }^{\circ} \mathrm{C}$. It is a precipitation hardened alloy where the main contribution to the strength comes from the gamma double prime $\left(\mathrm{Ni}_{3} \mathrm{Nb}\right)$ precipitates and to a minor extent from the gamma prime $\left(\mathrm{Ni}_{3}(\mathrm{Al}, \mathrm{Ti})\right)$ precipitates. A secondary phase, the delta-phase, is present at lower temperatures than $1000{ }^{\circ} \mathrm{C}$ and allows for grain size control during the metallurgical processing.

A $135 \mathrm{~mm}$ diameter bar from a single batch of material with the chemical composition as shown in Table 1 was cut into $40 \mathrm{~mm}$ thick discs. To allow for two different grain sizes to be tested one half part of the discs was preserved in the as received fine grain size state (16 $\mu \mathrm{m}$, ASTM 9) while the other half part was given a special high temperature heat treatment, the details of which is given in a previous paper [3], in order to make the small initial grains grow to a larger size (127 $\mu \mathrm{m}$, ASTM 3). A standard solution and age heat treatment was then carried out to bring the full hardness to the material [12]. Fig. 1 shows the microstructures achieved after these heat treatments and in

Table 2 the corresponding HV-hardness numbers are shown.

Table 1 Nominal composition of Alloy 718 and the composition of the bar, wt. \% [12]

\begin{tabular}{l|lllllllllllll} 
Alloy & $\mathrm{Ni}$ & $\mathrm{Cr}$ & $\mathrm{Co}$ & $\mathrm{Fe}$ & $\mathrm{C}$ & $\mathrm{Mo}$ & $\mathrm{Al}$ & $\mathrm{Ti}$ & $\mathrm{Nb}$ & $\mathrm{B}$ & $\mathrm{Mn}$ & $\mathrm{Si}$ & $\mathrm{Cu}$ \\
\hline Nominal & $\mathrm{Bal}$ & 19 & 0.0 & 18.5 & 0.04 & 3.0 & 0.5 & 0.9 & 5.1 & .006 & 0.2 & 0.2 & \\
Actual bar & $\mathrm{Bal}$ & 18.36 & 0.33 & 17.49 & 0.04 & 3.15 & 0.56 & 0.92 & 5.46 & .001 & 0.09 & 0.05 & 0.14
\end{tabular}
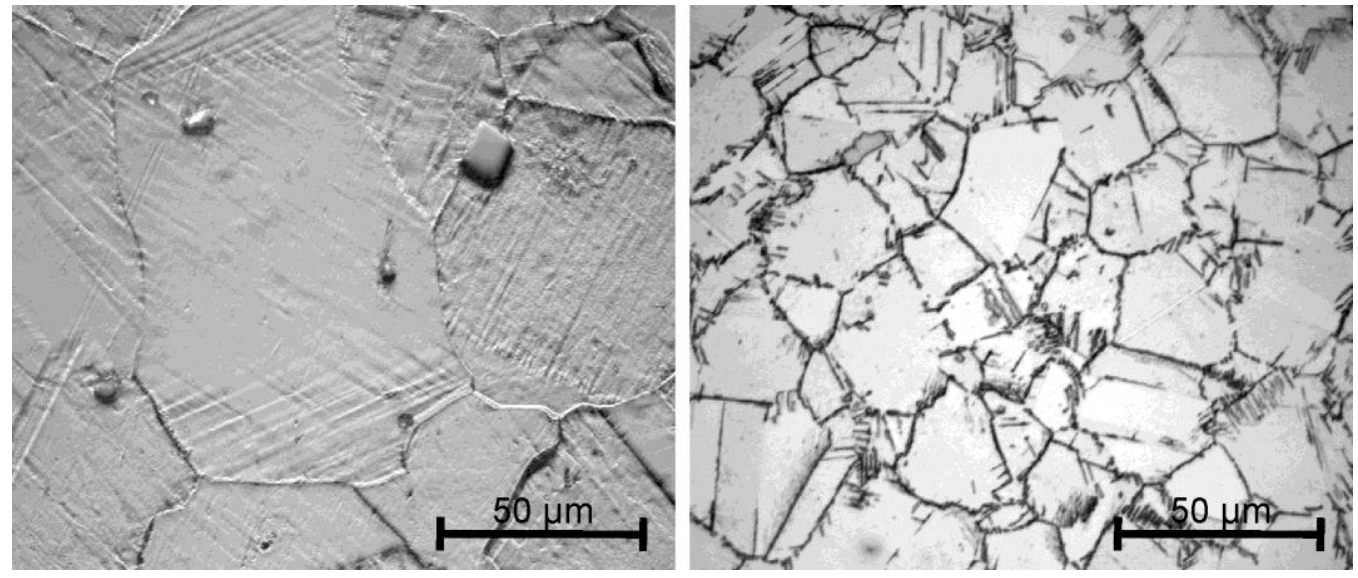

Fig. 1 Workpiece material microstructures, large grain size material (left) and small grain size material (right). 
Table 2 Grain size and hardness of heat treated discs

\begin{tabular}{|l|l|l|l|}
\hline Material & $\begin{array}{l}\text { Average } \\
\text { diameter }[\mu \mathrm{m}]\end{array}$ & $\begin{array}{l}\text { Grain size } \\
{[\mathrm{ASTM}]}\end{array}$ & $\begin{array}{l}\text { Hardness } \\
{[\mathrm{HV}]}\end{array}$ \\
\hline Large grains & 127 & 3 & 430 \\
\hline Small grains & 16 & 9 & 445 \\
\hline
\end{tabular}

\section{Machining}

Machining was performed on a EMCO 365 CNC lathe, with mineral oil based emulsion HysolXF, with a concentration of $6 \%$, applied. The inserts were uncoated standard cemented carbides without chip breaker (Sandvik Coromant TCMW16T304-H13A) with a $0.4 \mathrm{~mm}$ nose radius, $0^{\circ}$ rake angle and $91^{\circ}$ entering angle. Turning was performed at $30 \mathrm{~m} / \mathrm{min}$ cutting speed, a feed rate of either 0.1 or $0.2 \mathrm{~mm} /$ revolution and with $2 \mathrm{~mm}$ depth of cut. Each test had the same spiral cutting length (SCL) of $121 \mathrm{~m}$ accumulated in two passes. Two identical experiments were done for each test condition, i.e. with the same cutting parameters and microstructure.

The burr formation was studied after interrupted turning tests with 25 revolutions with new tools for each test and under the same cutting conditions as for the tool wear tests.

\section{Microscopic evaluation}

The notch wear, burr formation and the sideflow of the chips were measured in a Zeiss Discovery V20 stereomicroscope. A larger depth of focus was obtained by the technique of stacking images with different focus distances and using the AxioVision software. The notch wear was measured and reported as the maximum depth. The cross-sections of the burrs were studied by standard light optical microscopy.

The bottom and top views of the chips were analyzed in more detail using scanning electron microscopy (SEM - LEO 1550 Gemini).

\section{Results}

Fig. 2 shows stereo-optical micrographs of the flank and rake faces on inserts after machining the work material with large and small grains at the two feed rates 0.1 and $0.2 \mathrm{~mm} /$ revolution. Table 3 shows the notch wear measurements for both types of material and for both feed rates.

A notch develops at both feed rates in the large grain size material and with a larger wear at the high feed rate, as can be seen on both the tool rake faces and the flank faces. However, no notch is formed in the small grain size material at the low feed rate. At the high feed rate, in the same small grain size material, notch formation is evident, but significantly smaller than the notches in the large grain size material at the same feed rate. Hence, the work material grain size has a 
larger effect on the notch wear than the feed rate for the conditions here investigated. The obvious flank and crater wear as seen in Fig. 2 was not evaluated in the present study since the focus here is on the notch wear.
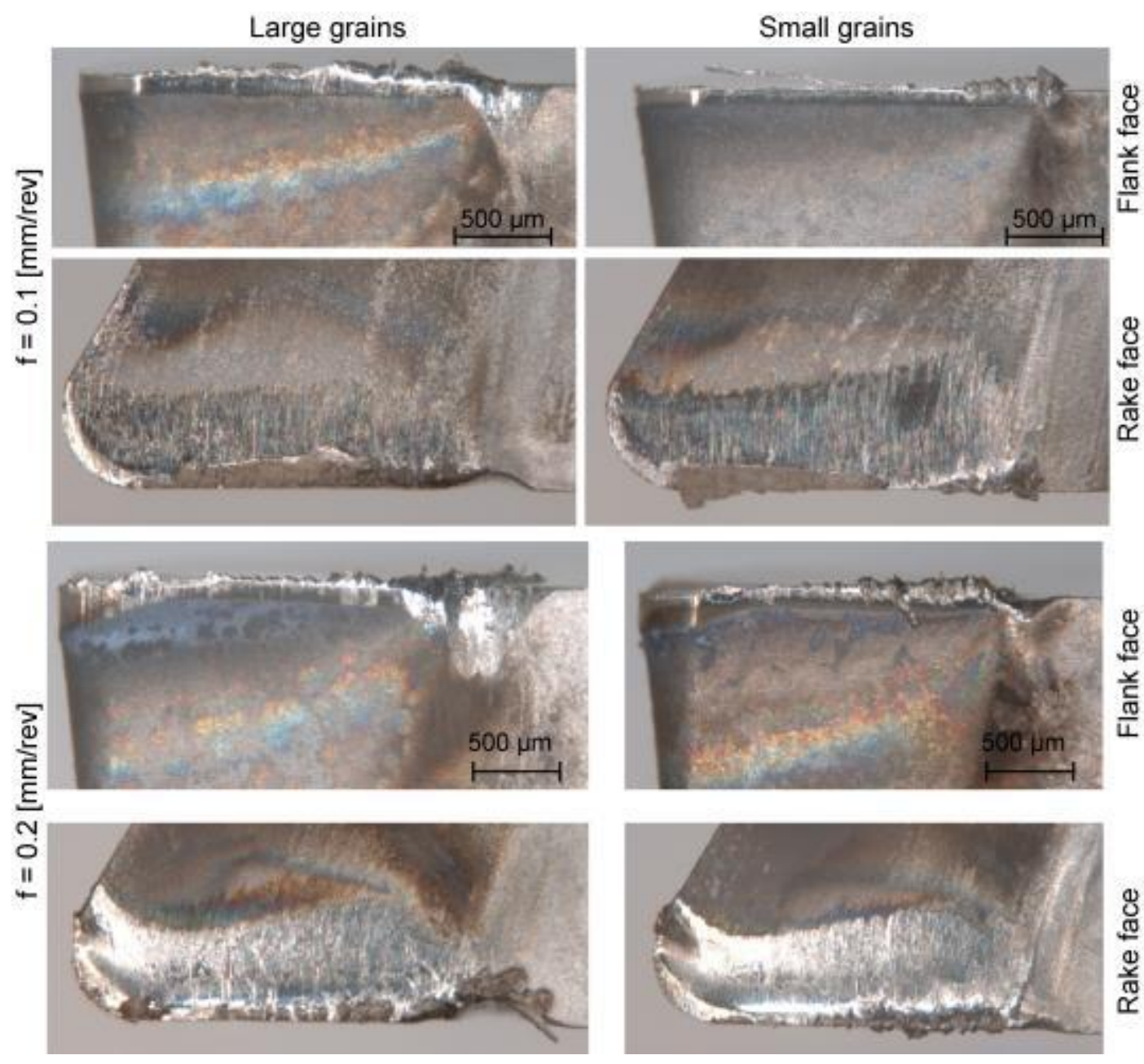

Fig. 2 Overview of tool flank and rake faces.

Table 3 Maximum notch wear $(\mu \mathrm{m})$ measured at the flank face for the two grain size conditions (small and large) at the two feed rates

\begin{tabular}{|c|c|c|}
\hline Feed rate $[\mathrm{mm} / \mathrm{rev}]$ & $\begin{array}{c}\text { Notch wear }[\mu \mathrm{m}] \\
\text { Large grain }\end{array}$ & $\begin{array}{c}\text { Notch wear }[\mu \mathrm{m}] \\
\text { Small grain }\end{array}$ \\
\hline 0.1 & $379 \pm 9$ & 0 \\
\hline 0.2 & $545 \pm 7$ & $109 \pm 34$ \\
\hline
\end{tabular}

The appearances of the top and bottom surfaces of the chips produced by the four different test conditions are compared in Fig. 3 . The chip morphology for the large grain size material is evidently serrated and relatively unaffected by the feed rate. The sideflow appearances, at the edge of the chip, are shown in Fig. $\mathbf{3}$ (b and c) at a larger magnification than in the a-figures. The sideflow increases with the feed rate as seen in Table 4 where the maximum chip width is reported. The chip morphology of the small grain size materials is smooth at both feed levels. 
However, the edges at the high feed rate have repeated localized deformation, as can be seen in Fig. 3 ( $b$ and $c$ ) and where the chip edge lamellas are also completely separated. Table 4 shows that the sideflow for the small grain size material as well as for the large grain size material increases with the feed rate.
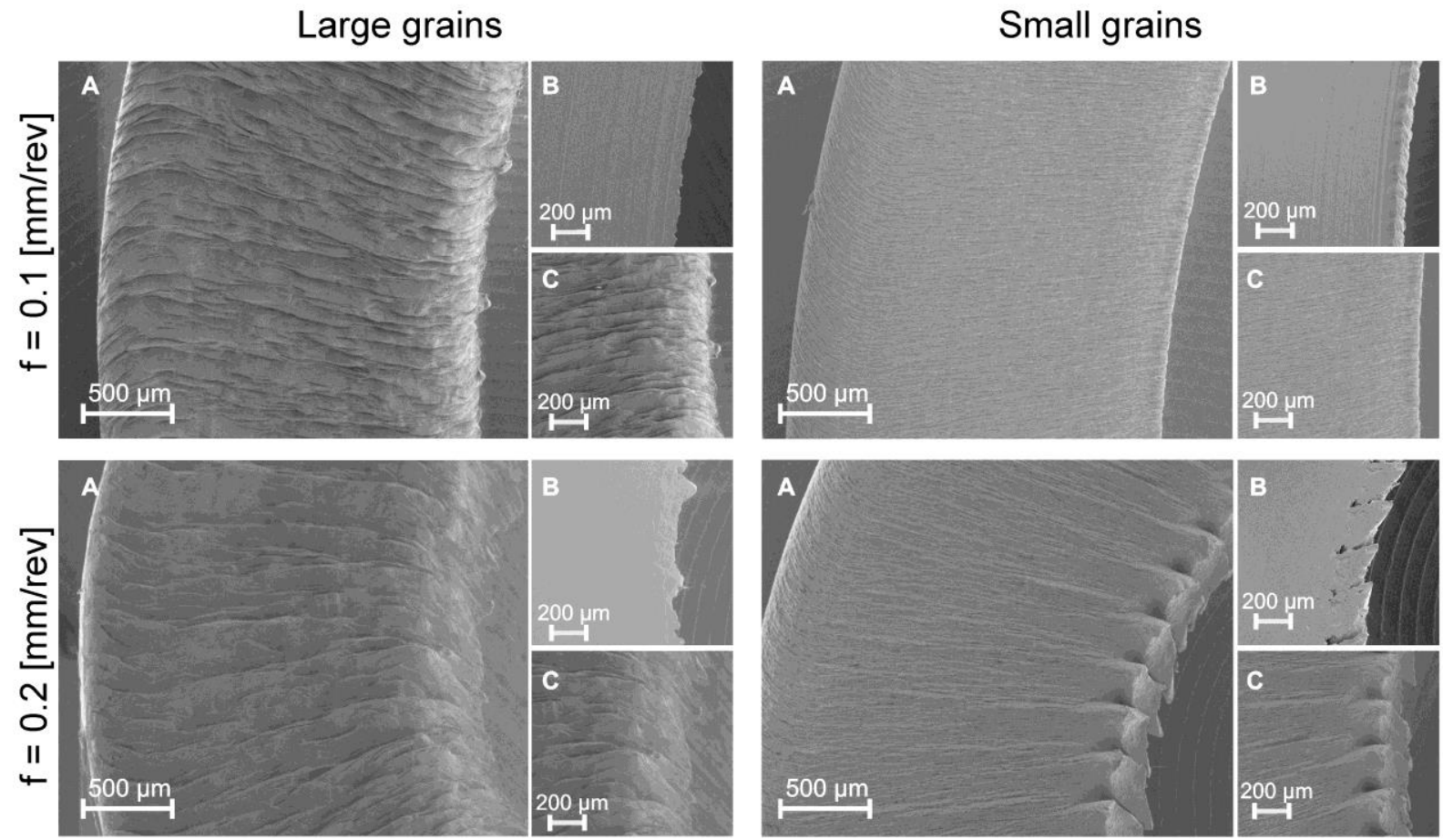

Fig. 3 Chip morphology appearance of the top view (a), the chip edge bottom view (b) and the chip edge top view (c).

Table 4 The chip sideflow $(\mu \mathrm{m})$ for the different test conditions

\begin{tabular}{|c|c|c|}
\hline $\begin{array}{c}\text { Feed rate } \\
{[\mathrm{mm} / \mathrm{rev}]}\end{array}$ & $\begin{array}{c}\text { Chip sideflow }[\mu \mathrm{m}] \\
\text { Large grain }\end{array}$ & $\begin{array}{c}\text { Chip sideflow }[\mu \mathrm{m}] \\
\text { Small grain }\end{array}$ \\
\hline 0.1 & 250 & 180 \\
\hline 0.2 & 490 & 400 \\
\hline
\end{tabular}

Fig. 4 illustrates the burr formation on the work material for the four different test conditions. For the large grain size material, burrs are formed at both feed rates. A noticeable difference was however observed; the burr formed at the low feed rate grows with each revolution, forming a built-up burr, while the burr from the previous cut was removed by the cut in the subsequent revolution at the higher feed rate. In the fine grain size material no burrs were formed at the low feed rate but at the larger feed rate with the associated segmented chip edges a matching saw toothed burr was found on the workpiece.

Metallographic cross sections of the burrs are shown in Fig. 5 which basically confirms the external appearances as shown in Fig. 4. It should though be noted that one single cross sections of the highly irregular shape of the burrs formed in the large grain size material at the low feed rate (as evident in Figure 4) is less representative than for the other three test conditions. However, the curly shape 
of the built up burr is a characteristic feature as compared with the burr formed with high feed rate which is hardly distinguishable in either figure.
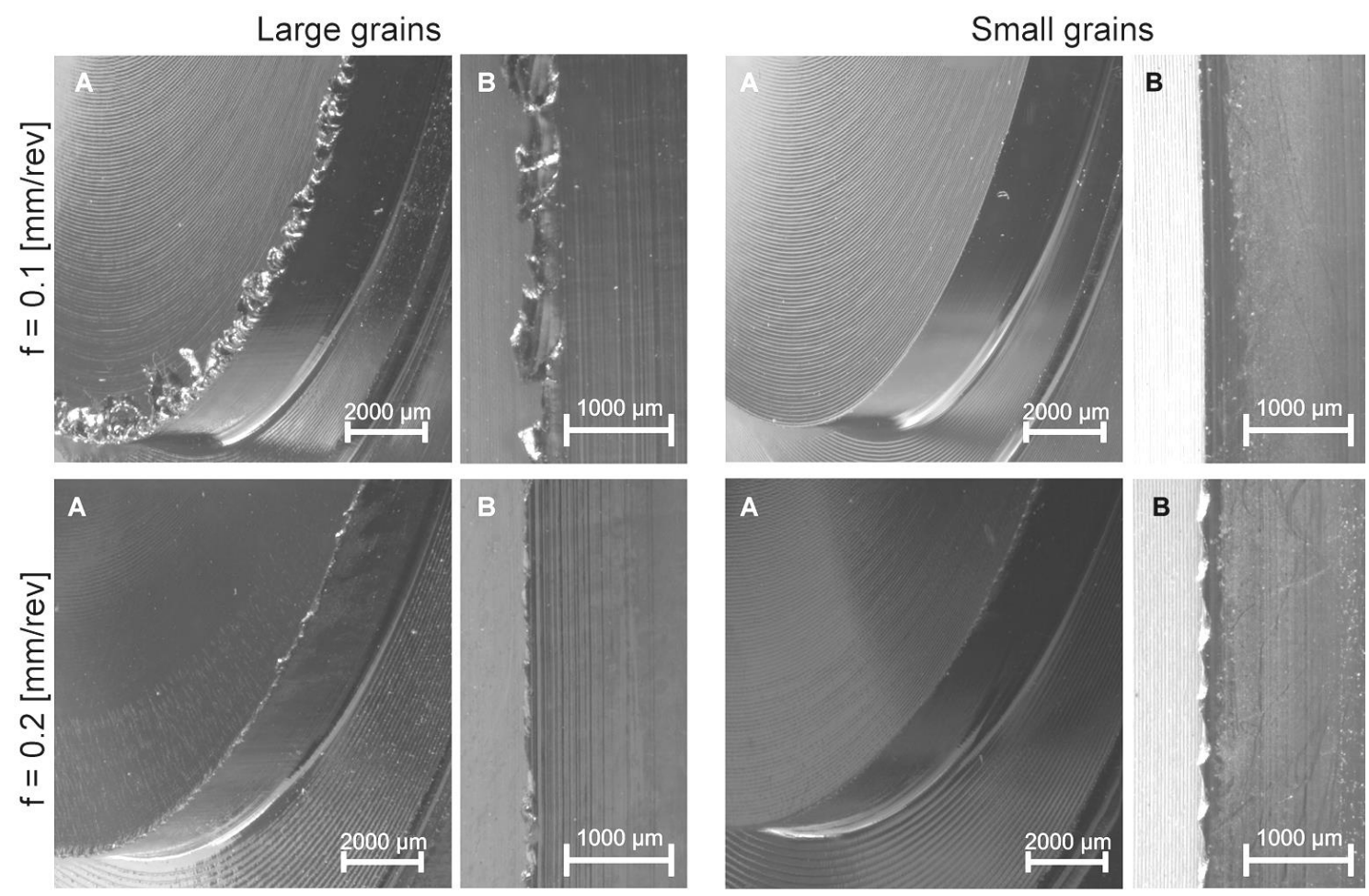

Fig. 4 Burr formation on the workpiece as machining was interrupted after 25 revolutions, low magnification (a) and a higher magnification side view (b).
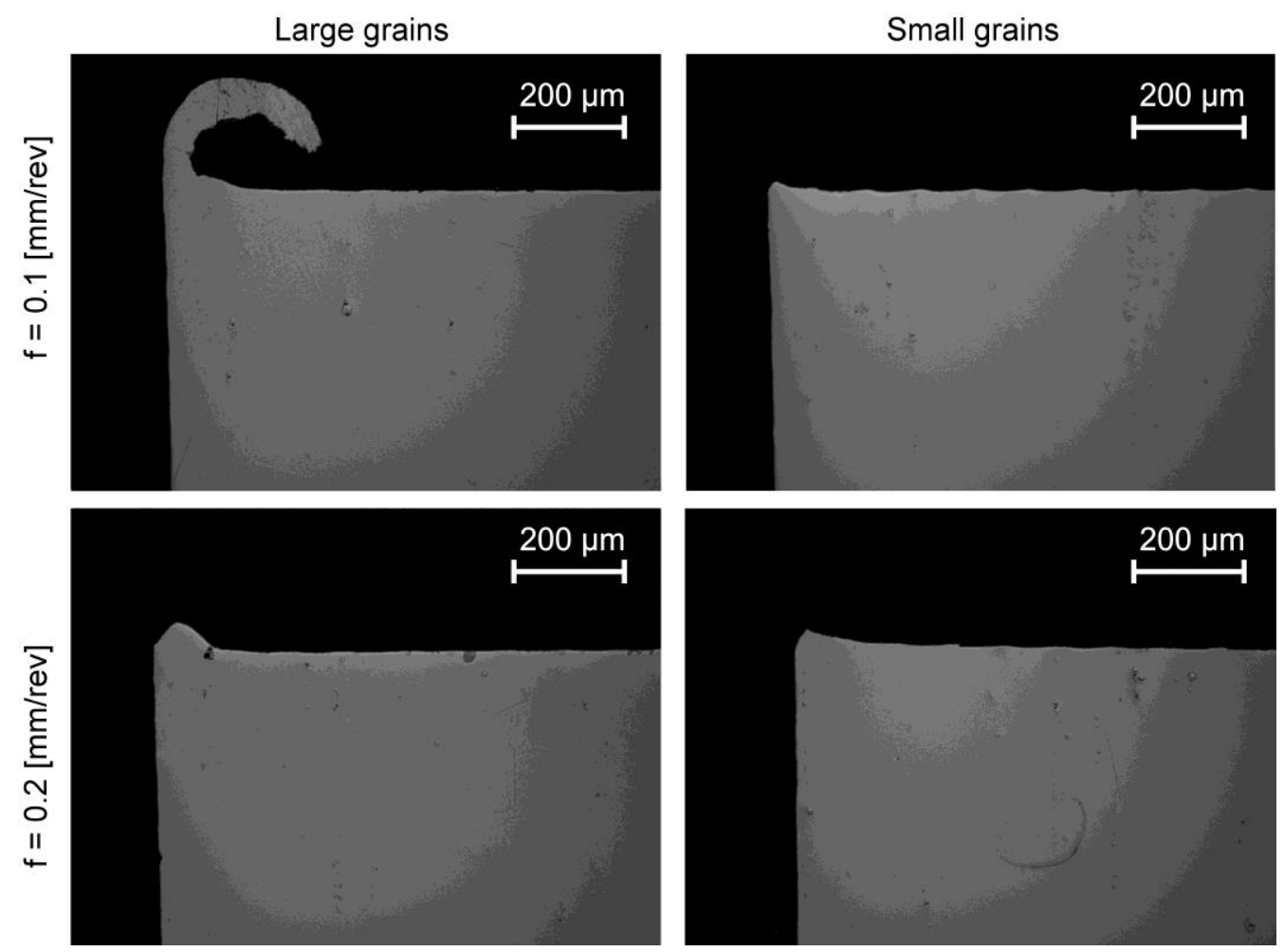

Fig. 5 Cross-section micrographs of the burr formation at the edge of the workpiece as machining was interrupted after 25 revolutions for the four test conditions. 


\section{Discussion}

In this study, the main objective was to investigate the effect of grain size of workpiece material and feed rate on the depth of cut notch and on the burr formation. The continuous smooth chip produced in the fine grain material at both feed rates indicates that the deformation has taken place homogeneously, which is not the case for the large grained material were serrated chips are produced. In the large grain size material the deformation is excessively anisotropic, since there are few adjacent grains which can restrain and mitigate the irregular deformation behaviour due to the fact that the grain size is in the same order of magnitude $(0.1 \mathrm{~mm})$ as the uncut chip thickness.

The influence of grain size on chip formation was investigated by Olovsjö et al. [3]. In their study, the work material was shown to deform anisotropically when the average grain size and chip thickness were of the same magnitude. In micromachining this is sometimes referred to as "anisotropic machining", i.e. when grain size is on the same order of magnitude as the uncut chip thickness [13]. There is also a transition from continuous to shear localized chip when cutting data is changed. At a critical cutting speed, the chip transforms from a continuous to a shear localized character and this speed is lower when the feed rate is higher $[9,10]$.

The results in the present study show that the criterion for shear localization is more easily met at the chip edges as seen in Fig. 3 . The segmentation at outer edges has also been observed by Dearnley et al. [14] as well as by Tönshoff et al [15]. A possible explanation for this is that the stress state of the chip, changes from plain strain in the shear zone at the center of the cutting zone to plain stress at the edge, thereby changing the plastic flow criteria [8]. Correlation between the burr and the chip sideflow was also found by Kitagawa et al.[5], who noted that the maximum of the sideflow and the burr height, when cutting speed was altered, coincided with a maximum of notch wear. They also found that there was a transition from a continuous type of chip to a segmented type when cutting speed was increased. In the investigation by Olovsjö et al. [3], the correlation between notch wear, burr formation and serrated chips was also observed, but the effect of the cutting data was not investigated.

In the present study no notch wear was developed at the low feed rate in the small grain size material, but with increasing feed rate a small notch developed. There is an evident correlation between the chip edge appearance and the shape of the burr. At the low feed both a smooth chip edge and burr was found while at the high feed, the chip edge consisted of separated lamellae with corresponding features of the burr (Figure 3 and Figure 4 in comparison).

Large notch wear at the depth of cut occurred at both feed rates for the large grain size material together with serrated chip edges. Notch wear and burr formation associate strongly with sideflow and serrated chip edges in this study. 
Clearly, the burr morphology is strongly influenced by the grain size of the material as well as by the cutting parameters, as described above. Large grains form large ragged burrs regardless of feed during each turn, but the building up of the burr formed at the low feed rate is a continuous process as shown in Fig. 6 but will basically be removed by the subsequent cut of the next revolution when the feed rate is larger $(0.2 \mathrm{~mm} /$ revolution) than the average grain size diameter (127 $\mu \mathrm{m})$ as was illustrated in Figure 4. There is, however, no burr buildup in the material with small grains, when feed rate is one order of magnitude larger than the actual grain size; 0.1 or $0.2 \mathrm{~mm} /$ revolution versus $16 \mu \mathrm{m}$.
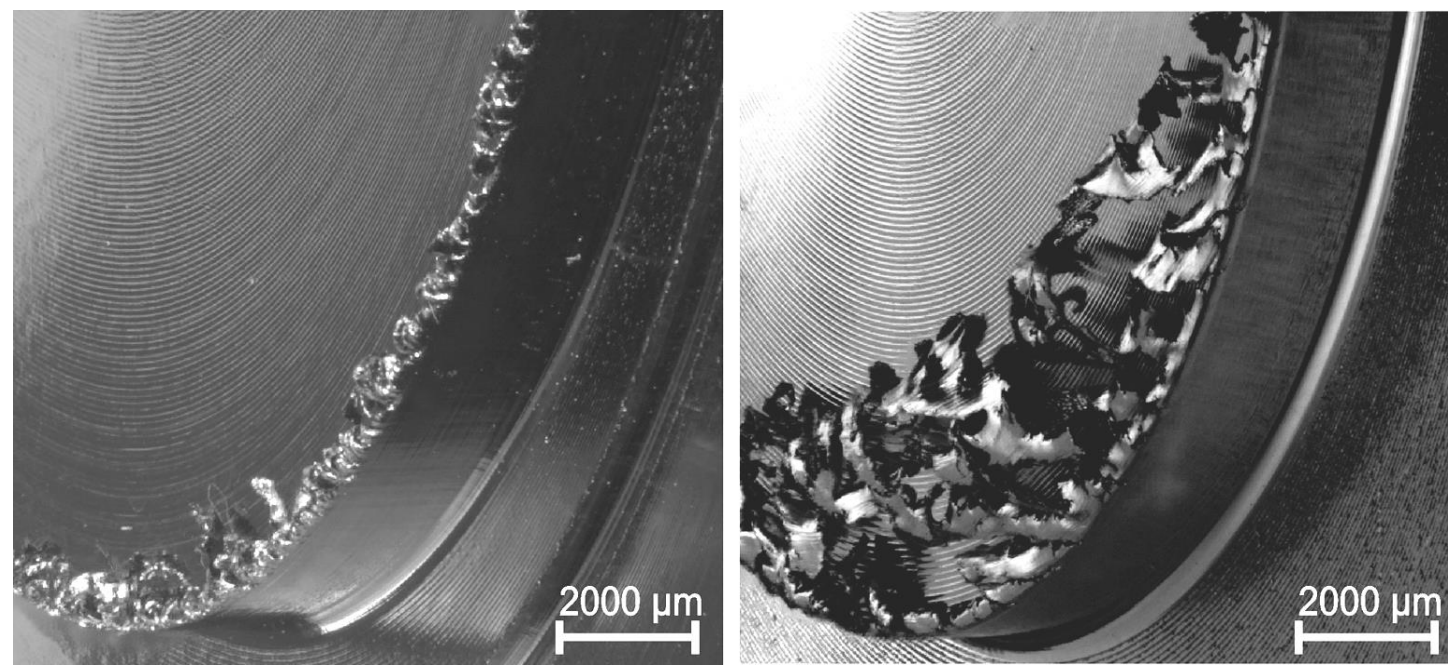

Fig. 6 Burr built-up as the machining was interrupted after 25 revolutions (left) and 400 revolutions (right).

Both the grain size of the workpiece and the feed rate has an influence on the sideflow, on the notch wear and on the burr formation. The chip edge morphology seems to be important, i.e. the combination of serrated, or lamellar, chip edges and the amount of sideflow. Fig. 7 shows the correlation between the amount of sideflow of the chips and the notch wear, the magnitude of which differs between the grain sizes. Such a correlation for each grain size can be understood by studying the difference in deformation characteristics at the edge of the chip for each grain size. These characteristics are influenced by both differences in mechanical properties due to the difference in grain size, as well as the addition of anisotropic deformation behavior in the large grains. 


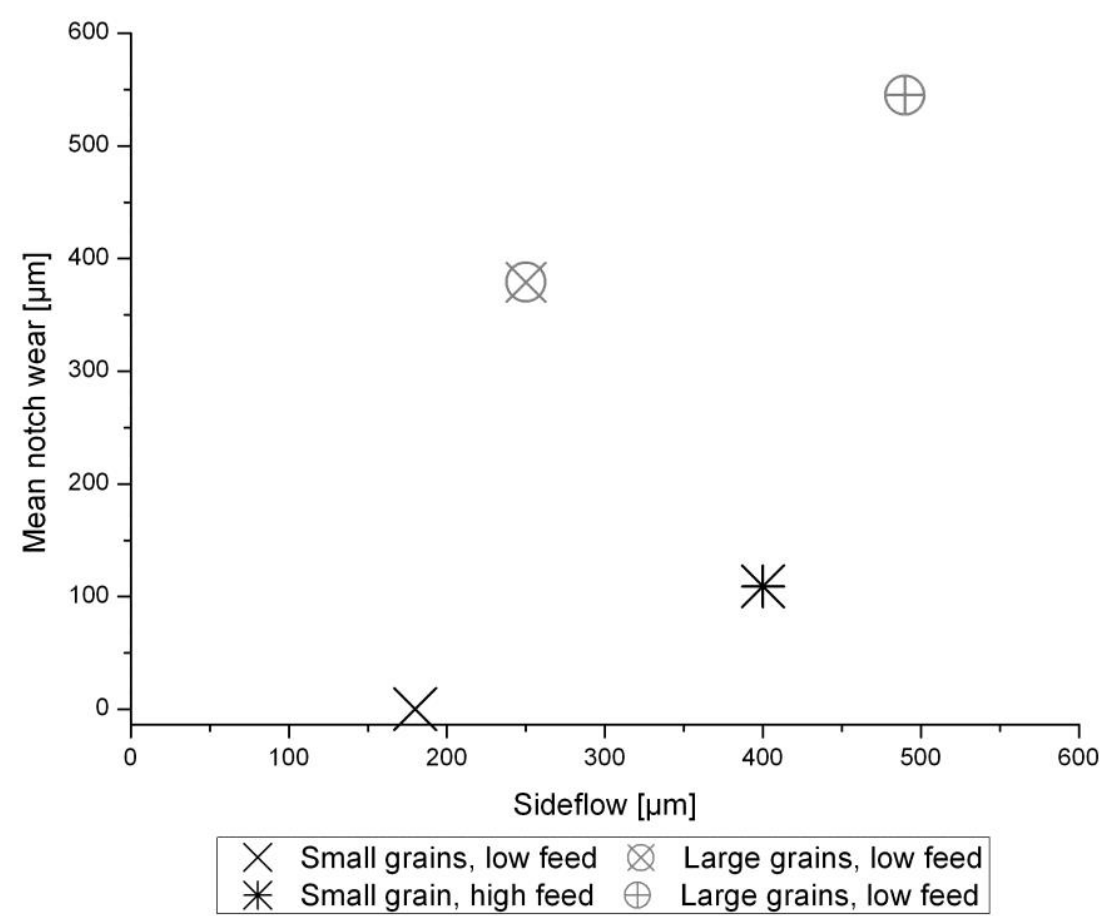

Fig. 7 Mean notch wear versus chip sideflow.

It does not seem that the burrs, per se, have any influence on the notch formation since the largest burrs develop in the large size grain material at low feed, whereas the largest notch is found at the high feed with basically no burr buildup. Still, large grains do, however, result in large ragged burrs as well as large notch wear at both feed rates but no build-up at the lower one.

\section{Conclusions}

Under the tested conditions the following conclusions can be drawn regarding the influence of grain size and feed rate on side flow, notch wear and burr formation.

- Notch wear and the side flow increase with the feed rate regardless of the grain size.

- Grain size influences notch wear more than feed rate under the tested conditions.

- High feed rate gives segmentation at chip edges in small grain size material as well as notch wear and limited burr formation.

- Large grain material associates with inhomogeneous deformation and serrated chips. 
- Low feed rate combined with large grains (feed rate less than average grain size) results in a burr that is continuously built-up for each revolution of the workpiece.

\section{Acknowledgements}

This work was performed as a part of the OPTIMA two and Pro-Viking Short-Cut projects, the authors thank VINNOVA and SSF for the financial support. The work forms also a part of the strategic initiative in production at Chalmers University of Technology, which is gratefully acknowledged.

\section{References}

1. Ezugwu EO, Wang ZM, Machado AR (1999) The machinability of nickel-based alloys: A review. Journal of Materials Processing Technology 86 (1-3):1-16

2. Sims CT, Stoloff NS, Hagel WC (1987) Superalloys II. Wiley, New York

3. Olovsjö S, Wretland A, Sjöberg G (2010) The effect of grain size and hardness of wrought Alloy 718 on the wear of cemented carbide tools. Wear 268 (9-10):1045-1052

4. Dornfeld D, Min S (2005) A Review of Burr Formation in Machining. In: Burrs - Analysis, Control and Removal. Springer Berlin Heidelberg, pp 3-11. doi:10.1007/978-3-642-00568-8_1

5. Kitagawa T, Kubo A, Maekawa K (1997) Temperature and wear of cutting tools in high-speed machining of Inconel 718 and Ti-6AI-6V-2Sn. Wear 202 (2):142-148

6. Moltrecht KH (1964) Turning of high temperature alloys, technical paper No. 637. Paper presented at the American Society of tool and manufacturing engineers, Annual Meeting, Detroit, April

7. Lee M, Horne JG, Tabor D (1979) Mechanism of Notch Formation at the Depth of Cut Line of Ceramic Tools Machining Nickel Base Superalloys. Electric Power Research Institute (Report) EPRI EL:460-469

8. Shaw MC, Thurman AL, Ahlgren HJ (1966(May)) A Plasticity Problem Involving Plane Strain and Plane Stress Simultaneously: Groove Formation in the Machining of High-Temperature Alloys. Transactions of the ASME:142-146

9. Burns TJ, Davies MA (2002) On repeated adiabatic shear band formation during high-speed machining. International Journal of Plasticity 18 (4):487-506

10. Komanduri R, Hou ZB (2002) On thermoplastic shear instability in the machining of a titanium alloy (Ti-6Al-4V). Metallurgical and Materials Transactions A: Physical Metallurgy and Materials Science 33 (9):2995-3010

11. Schirra JJ, Viens DV Metallurgical Factors Influencing the Machinability of Inconel 718. In: Loria EA (ed) Superalloys 718, 625, 706 and Various Derivatives, Pittsburgh, Pennsylvania; United States., 1994.

12. Aerospace S, Aerospace Material Specification 5662M. 1965. p. 11.

13. Dornfeld D, Min S, Takeuchi Y (2006) Recent Advances in Mechanical Micromachining. CIRP Annals - Manufacturing Technology 55 (2):745-768

14. Dearnley PA, Trent EM (1982) Wear mechanisms of coated carbide tools. Metals Technology 15. Tönshoff HK, Brinksmeier E, Bartsch S (1987) Notch Wear and Chemically Induced Wear in Cutting with Al2O3-Tools. CIRP Annals - Manufacturing Technology 36 (2):537-541 